\title{
Vibriosis vaccination of rainbow trout Salmo gairdneri at varying temperatures and seasons. II. Effects on antibody production in five Swedish field trials
}

\author{
Margaret A. Thorburn ${ }^{1, *}$, Eva Jansson ${ }^{2}$, Ann Thuvander ${ }^{3}$ \\ ${ }^{1}$ Department of Epidemiology and Preventive Medicine, School of Veterinary Medicine, University of California, Davis, \\ California 95616, USA \\ ${ }^{2}$ National Veterinary Institute, Box 7073, S-750 07 Uppsala, Sweden \\ ${ }^{3}$ Department of Pathology, School of Veterinary Medicine, Uppsala, Sweden
}

\begin{abstract}
Vibriosis vaccine trials were conducted on 5 Swedish brackish water rainbow trout Salmo gairdneri net-pen farms. Blood samples were collected from trial fish on several occasions and the level of anti-Vibrio anguillarum serotype 1 antibodies tested with ELISA. Results were used to classify fish as sero-negative (low titre) or -positive (high titre). A high percentage ( $\geqslant 75 \%$ ) of trout in all IP-vaccinated groups were sero-positive during most of the growing season. The percentage of sero-positives among sampled pre-outbreak dip-vaccinated trout was lower $(\leqslant 27 \%)$. Fish in some non-vaccinated groups began to develop high titres after placement in brackish water and prior to, or in the absence of, vibriosis outbreaks. The vaccinated and non-vaccinated populations which experienced the lowest vibriosis-specific mortality rates during the first growing season were those showing the highest preoutbreak percentages of sero-positive fish.
\end{abstract}

\section{INTRODUCTION}

Vibriosis control programs in salmonids frequently incorporate vaccination (Evelyn 1984) and husbandry factors, such as decreasing rearing densities and minimal handling. Where possible, farmers may attempt to minimize the vibriosis risk by introducing fish to salt/ brackish water during periods of low water temperature, or by purchasing larger fish (Thorburn et al. 1987). However, the success of such measures in reducing vibriosis losses has thus far only been assessable retrospectively. Farmers trying unproven control methods would benefit if the protective immunity of fish could be tested prior to the occurrence of vibriosis. Unfortunately, there is relatively poor correlation between various immune assays and protection against vibriosis in laboratory-tested fish (Tatner \& Horne 1986).

Tests on the performance of immune assays in field

\footnotetext{
- Present address: National Veterinary Institute, Box 7073, S-750 07 Uppsala, Sweden
}

situations have generally been limited to the determination of anti-Vibrio anguillarum titres. Most reports in salmonids have only presented data as mean titers of fish samples (Antipa 1976, Antipa \& Amend 1977. Baudin-Laurencin \& Tangtrongpiros 1980, RosenkvistJensen 1983). The mean, however, is very sensitive to extreme values (Remington \& Schork 1970). For instance, the occurrence of a small proportion of fish with very high titres would yield a relatively high mean titre value, obscuring the potential fact that most fish yielded no, or very low titres. The proportions of fish with high titers and negative or low titres may give a better indication of the ability of a population to resist disease.

The purpose of this study was to monitor anti-Vibrio anguillarum antibodies in selected populations of vaccinated and non-vaccinated rainbow trout. Using an enzyme-linked immunosorbent assay (ELISA), the prevalences of fish with high titres were repeatedly estimated over the course of a growing season, and considered in relation to vibriosis-specific mortality rates. 


\section{MATERIALS AND METHODS}

Fish. The fish on three of the rainbow trout Salmo gairdneri farms (Farms A, B, and C) included in this study were described in an earlier paper (Thorburn et al. 1988). Blood sample results from vaccinated and non-vaccinated rainbow trout on 2 additional farms (Farms $\mathrm{E}$ and $\mathrm{F}$ ), which had minimal vibriosis mortality in non-vaccinated fish $0.05 \%$ on Farm $F$, no vibriosis detected on Farm E), are also included in the present report. Table 1 presents the 5 farms' vaccination schemes.

Blood samples. We first collected blood, where possible, from samples of trial non-vaccinated fish at their respective freshwater hatcheries, 2 to $3 \mathrm{wk}$ prior to transport (Farms A [November transport fish], B, C, and E), and again within $5 \mathrm{~d}$ of delivery to brackish water (Farms A [July transport fish], B, and E). Subsequent samples from both vaccinated and non-vaccinated groups were collected on 2 to 4 separate occasions on each farm. Blood samples were taken from the caudal vessels of 10 to 25 fish in each vaccination group, at each farm visit. The samples were allowed to clot overnight at $4{ }^{\circ} \mathrm{C}$, and then centrifuged at $300 \times g$ for 12 min. The sera were stored at $-20^{\circ} \mathrm{C}$ until tested with the ELISA.

ELISA. The method is described in detail by Thuvander et al. (1987) and is therefore only outlined here. Rabbit anti-trout antibodies conjugated to horseradish peroxidase were prepared as described. Polystyrene microtitre plates (Lanbro, Flow) were coated with Vibrio anguillarum serotype 1 (as classified by Sørensen \& Larsen 1986) O-antigen. The plates were incubated overnight at room temperature, then washed 3 times in washing fluid. Subsequently $100 \mu \mathrm{l}$ of fish serum (diluted 1:100 in PBS with $0.5 \%$ Tween 20) was added to each of the wells. Duplicate wells were used for each serum sample. After incubation at $4^{\circ} \mathrm{C}$ for $20 \mathrm{~h}$, the plates were washed 3 times and rabbit anti-trout IgM conjugated to horseradish peroxidase (diluted in PBS containing $0.5 \%$ Tween 20 and $1 \%$ horse serum) was added to each well. The plates were incubated at $4{ }^{\circ} \mathrm{C}$ for 15 to $20 \mathrm{~h}$. After washing, trimethylbenzidine (TMB, Sigma) in acetate buffer with $\mathrm{H}_{2} \mathrm{O}_{2}$ was added to the microtitre wells. The reaction was stopped with $\mathrm{H}_{2} \mathrm{SO}_{4}$ and the optical density was read spectrophotometrically at $450 \mathrm{~nm}$.

Control sera. Control positive and negative sera were included in triplicate on every plate. These pooled sera originated from rainbow trout reared in flowing pathogen-free ground water aquaria; 'positive' trout had been repeatedly injected with a formalinkilled vibriosis bacterin.

Classification procedure. We used ELISA absorbance $\left(O D_{450}\right)$ values to classify individual fish as sero- positive or sero-negative. Fish showing titres lower than a cutpoint (C) defined as the mean $\mathrm{OD}_{450}$ plus 1.96 standard deviation (SD) $\mathrm{OD}_{450}$ of representative negative fish were classified as sero-negative; those showing higher titres were classified as sero-positive. The mean and $\mathrm{SD} O D_{450}$ of representative negative rainbow trout populations were estimated from the following samples: (1) negative samples for Farms A (1985), B and $\mathrm{C}$ originated from their respective freshwater samplings and Farm B's first brackish water sampling; (2) negative samples for Farm A (1984) originated from the initial Farm A brackish water sampling; (3) negative samples for Farms $\mathrm{E}$ and $\mathrm{F}$ originated from farm $\mathrm{E}$ 's freshwater and initial brackish water samplings.

Variations in $\mathrm{OD}_{450}$ values among microtitre plates were corrected to the plate(s) containing the representative negative population. This was achieved by adjusting the cutpoint defined above according to the following formula:

$$
C_{y}=N_{y}+\left(P_{y}-N_{y}\right) \frac{C_{n}-N_{n}}{P_{n}-N_{n}}
$$

where $C_{y}=$ the adjusted cutpoint on plate ' $y$ '; $N_{y}=$ the mean $\mathrm{OD}_{450}$ value of the 3 wells containing negative control serum on plate ' $y$ '; $P_{Y}=$ the mean $O_{450}$ value of the 3 wells containing positive control serum on plate ' $y$ ' $; C_{n}=$ the cutpoint determined from the plate (' $n$ ') containing the representative negative population; $N_{n}=$ the mean $O_{450}$ value of the 3 wells containing negative control serum on plate ' $n$ '; $P_{n}=$ the mean $\mathrm{OD}_{450}$ value of the 3 wells containing positive control serum on plate ' $n$ '.

Classification accuracy. Poor sensitivity could arise as a result of the classification procedure, if the negative samples used to define the positive-negative cutpoints yielded falsely high $\mathrm{OD}_{450}$ readings (due, for instance, to non-specific antibody binding). We therefore compared the absorbance values of all such negative samples to those of the 3 wells on the respective plate containing the known negative sera from pathogen-free fish.

Poor specificity could arise if trial trout encountered, and responded immunologically to, cross-reacting antigens to Vibrio anguillarum during brackish water rearing. We therefore routinely checked moribund fish on all participating farms for the presence of bacterial pathogens other than $V$ anguillarum.

\section{RESULTS}

Results of the ELISA-based classifications are summarized in Table 2. Table 2 also presents the dates of vibriosis outbreaks and the vibriosis-specific mortality 
Table 1. Salmo gairdneri. Summary of vibriosis vaccine trials on Swedish brackish-water commercial rainbow trout net-pen farms, $1984-1985$

\begin{tabular}{|c|c|c|c|c|c|c|}
\hline \multirow[t]{2}{*}{ Farm } & \multirow[t]{2}{*}{ Group } & \multicolumn{4}{|c|}{ Vaccination } & \multirow{2}{*}{$\begin{array}{l}\text { Date of transport } \\
\text { to net-pen farm }\end{array}$} \\
\hline & & Size $(g)$ & Method & Date & Water temp. $\left({ }^{\circ} \mathrm{C}\right)$ & \\
\hline \multirow[t]{5}{*}{ A. } & V1 & 2.3 & $\operatorname{dip}$ & 22 May 84 & 16 & 5 July 84 \\
\hline & $\mathrm{C} 1$ & - & - & Control & - & 5 July 84 \\
\hline & $\mathrm{V} 2$ & 2.3 & dip & 22 May 84 & 16 & 30 Nov 84 \\
\hline & V3 & 95 & IP & 1 Nov. 84 & 11 & 30 Nov 84 \\
\hline & $\mathrm{C} 2$ & - & - & Control & - & 30 Nov 84 \\
\hline \multirow[t]{2}{*}{$B$} & V1 & 85 & IP & 6 Jun 85 & 14 & 28 Jun 85 \\
\hline & $\mathrm{C} 1$ & - & - & Control & - & 28 Jun 85 \\
\hline \multirow[t]{3}{*}{$\mathrm{C}$} & V1 & 45 & IP & 8 May 85 & 3 & 14 Jun 85 \\
\hline & $\mathrm{V} 2$ & 55 & IP & 23 May 85 & $10^{\mathrm{a}}$ & 14 Jun 85 \\
\hline & $\mathrm{C} 1$ & - & - & Control & - & 14 Jun 85 \\
\hline \multirow[t]{2}{*}{$\mathrm{E}$} & V1 & 100 & IP & 25 Apr 84 & 9 & 15 May 84 \\
\hline & $\mathrm{C} 1$ & - & - & Control & - & 15 May 84 \\
\hline \multirow[t]{2}{*}{$\mathrm{F}$} & $\mathrm{V} 1$ & 97 & IP & 24. Apr 84 & 11 & 9 May 84 \\
\hline & C1 & - & - & Control & - & 9 May 84 \\
\hline
\end{tabular}

Table 2. Salmo gairdneri. Summary of vibriosis occurrence and of estimated proportions of anti-Vibrio anguillarum serotype 1 (VA) positive rainbow trout based on ELISA results from Swedish commercial brackish water farms participating in vibriosis vaccine trials

\begin{tabular}{|c|c|c|c|c|c|c|c|c|}
\hline \multirow{2}{*}{$\begin{array}{l}\text { Farm, } \\
\text { year }\end{array}$} & \multirow[t]{2}{*}{ Group ${ }^{a}$} & \multicolumn{4}{|c|}{$\%$ positive at sampling date: } & \multirow{2}{*}{$\begin{array}{l}\text { Date of } 1 \text { st } \\
\text { VA isolation }\end{array}$} & \multirow{2}{*}{$\begin{array}{c}\text { Vibriosis } \\
\text { specific mor- } \\
\text { tality rate (\%) }\end{array}$} & \multirow{2}{*}{$\begin{array}{l}\mathrm{OTC}^{\mathrm{b}} \\
\text { used }\end{array}$} \\
\hline & & $10 \mathrm{Aug}$ & $13 \mathrm{Sep}$ & $20 \mathrm{Oct}$ & $23 \mathrm{Nov}$ & & & \\
\hline $\mathrm{A}$ & V1 & 27 & 14 & 31 & 64 & 1 Oct & 7.1 & No \\
\hline \multirow[t]{2}{*}{1984} & $\mathrm{C} 1$ & 0 & 6 & 57 & 47 & 25 Sep & 10.7 & Yes \\
\hline & & $26 \mathrm{Jun}$ & $28 \mathrm{Aug}$ & & & & & \\
\hline A & V1 & 50 & 36 & & & Not done & $\leq 1.1$ & No \\
\hline \multirow[t]{5}{*}{1985} & $\mathrm{C} 1$ & 0 & - & & & Not done & $\leq 1.9$ & No \\
\hline & $\mathrm{V} 2$ & 10 & 29 & & & $16 \mathrm{Jul}$ & 7.1 & No \\
\hline & $\mathrm{C} 2$ & 0 & 18 & & & $16 \mathrm{Jul}$ & 7.5 & No \\
\hline & V3 & 100 & 100 & & & Not done & $\leq 0.3$ & No \\
\hline & & $7 \mathrm{Jul}$ & $20 \mathrm{Aug}$ & $17 \mathrm{Sep}$ & & & & \\
\hline B & V1 & 100 & 88 & 60 & & Neg. & 0 & No \\
\hline \multirow[t]{2}{*}{1985} & $\mathrm{C} 1$ & 5 & 11 & 4 & & $28 \mathrm{Aug}$ & 3.9 & Yes \\
\hline & & 20 Jun & $30 \mathrm{Sep}$ & & & & & \\
\hline$C$ & V1 & 75 & 71 & & & Neg. & 0 & No \\
\hline \multirow{3}{*}{1985} & V2 & - & 74 & & & Neg. & 0 & No \\
\hline & $\mathrm{C} 1$ & 0 & 31 & & & 26 Aug & 5.1 & Yes \\
\hline & & $17 \mathrm{Jun}$ & $\underline{20 \mathrm{Jul}}$ & $16 \mathrm{Aug}$ & $21 \mathrm{Sep}$ & & & \\
\hline \multirow{3}{*}{$\begin{array}{c}E \\
1984\end{array}$} & $\mathrm{~V} 1$ & 100 & 73 & 85 & 88 & Neg. & 0 & No \\
\hline & $\mathrm{C} 1$ & 11 & 87 & 43 & 47 & Neg. & 0 & No \\
\hline & & $15 \mathrm{Jun}$ & $19 \mathrm{Jul}$ & $17 \mathrm{Aug}$ & $22 \mathrm{Sep}$ & & & \\
\hline F & V1 & 82 & 95 & 90 & 94 & Neg. & 0 & No \\
\hline 1984 & $\mathrm{Cl}$ & 11 & 38 & 82 & 36 & $17 \mathrm{Aug}$ & $<0.1$ & Yes \\
\hline
\end{tabular}


rates for each farm, data which should be considered in relation to the titre results. Certain trends are presented below.

\section{Intraperitoneal (IP)-vaccinated trout}

All groups vaccinated via IP injection (A/V3, B/V1, C/V1, C/V2, E/V1, and F/V1) yielded high initial percentages ( 75 to $100 \%$ ) of sero-positive (\% pos.) fish. Furthermore, although vibriosis mortalities occurred in corresponding control fish on Farms A, B, C, and $F$, no vibriosis was detected in any of the IP-vaccinated fish.

The direction and magnitude of change in $\%$ pos. among IP-vaccinated fish over the course of the growing season varied slightly among farms.

\section{Dip-vaccinated trout}

The dip-vaccinated July-transport group (A/V1) had $27 \%$ sero-positive fish in the sample bled in August, $11 \mathrm{wk}$ after vaccination. This percentage had decreased slightly a month later, but later increased substantially during a prolonged vibriosis outbreak. These fish showed some protection relative to the nonvaccinated fish $(\mathrm{A} / \mathrm{C} 1)$, which yielded no sero-positive fish at the August sampling.

There was still a high \% pos. (50\%) in Group A/V1 when sampled early the following summer. This percentage can be compared to that of their cohort dipvaccinated group (A/V2), which had been transported to brackish water in the late fall, after the vibriosis outbreak, and which yielded a $\%$ pos. of only $10 \%$ at the same sampling. Group A/V1 with the higher proportion of sero-positive fish suffered fewer vibriospecific mortalities.

\section{Non-vaccinated trout with lowest mortality rates}

Some sero-positive fish (11\%) were identified among the non-vaccinated (C1) fish on Farms $E$ and $F$ at samplings conducted ca 1 mo after transport. These percentages were substantially higher in subsequent samples. On Farm E the \% pos, reached a peak of $87 \%$ in late July No vibriosis was detected in these fish at any time during the sampling period. The $\%$ pos. on Farm $F$ was also fairly high in late July $(38 \%)$. Farm F's peak $\%$ pos. $(82 \%)$ was noted in mid-August, simultaneous with the first isolation of vibriosis from these fish. Vibriosis-specific mortalities were, however, very low $(0.05 \%)$.

\section{Non-vaccinated trout with higher mortality rates}

Samples obtained 8 to $12 \mathrm{~d}$ prior to the start of vibriosis outbreaks on Farms A (1984) and B yielded small percentages of sero-positive fish $(6 \%$ and $11 \%$, respectively), which were slightly higher than those found in earlier samples from the same fish $10 \%$ and $5 \%$, respectively).

With the exception of Farm B, substantial increases in the \% of sero-positives were found in the control groups after periods with relatively high vibriosisspecific mortality rates $(\mathrm{A}[1984] / \mathrm{C} 1$, from 6 to $57 \%$; $\mathrm{A}[1985] / \mathrm{C} 2$, from 0 to $18 \% ; \mathrm{C} / \mathrm{C} 1$, from 0 to $31 \%$ ). Farm A's Group C1 was the only group of non-vaccinated fish sampled several months after an outbreak; at this time the \% pos. had decreased to zero.

\section{Accuracy}

Of the 54 samples designated as representative negative samples in the classification procedure, 45 $(83 \%)$ had $\mathrm{OD}_{450}$ values lower than the mean $\mathrm{OD}_{450}$ value of the negative control sera. An additional 7 $(13 \%)$ had values lower than the mean control value plus $1 \mathrm{SD}$ and $2(4 \%)$ had higher values.

No bacterial pathogens other than Vibrio anguillarum were detected on any of the participating farms during the study.

\section{DISCUSSION}

Joint occurrences of high titre levels and good protection against vibriosis in field-tested salmonids have been observed previously (Antipa 1976, Antipa \& Amend 1977). In the present study, the highest proportions of fish with high titres were found among those populations which experienced the lowest levels of vibriosis mortalities. Most of these populations had been IP-vaccinated. We also noted, however, high titre levels in substantial proportions of the trout sampled from the 2 non-vaccinated populations which experienced minimal, or no, vibriosis (Farms $E$ and F). These populations showed no or insignificant vibriosis mortalities. It would appear that environmental concentrations of Vibrio anguillarum were high enough on Farms $E$ and $F$ to induce observable primary humoral responses in many of the non-vaccinated fish. It is possible that prolonged exposure to moderately low concentrations of the pathogen allowed fish time to mount an immune response sufficient to avoid mortality. The remaining non-vaccinated populations (Farms A, B, and C), on the other hand, yielded no, or very few, sero-positives in pre-outbreak samplings, 
and experienced significant (for Sweden) vibriosis mortality rates.

The proportions of non-vaccinated fish showing high antibody titres following vibriosis outbreaks varied among farms. The short duration of several outbreaks may have limited the extent of pathogen exposure actually received by outbreak survivors, thus reducing the number of fish which developed humoral immune responses. Also, the amount of time elapsed between an outbreak and blood sampling could have affected the percentage of sero-positive fish detected (Antipa \& Amend 1977). In particular, the very low proportion of post-outbreak sero-positives observed among Farm B's non-vaccinated fish may have been partly due to this factor, especially since temperatures were quite low $\left(11^{\circ} \mathrm{C}\right)$, and declining, at the time of the outbreak.

It is possible that the differences observed in antibody production among the 5 farms' trout may be ascribed, in part, to genetic factors. The farms had purchased study fish from 5 different freshwater hatcheries (note, however, that vaccinated and non-vaccinated fish on each farm, except $F$, were full-siblings). Refstie (1982) found differences in anti-vibriosis antibody production among families of rainbow trout with different sires. Other workers have also reported among-stock differences in resistance to vibriosis (Gjedrem \& Aulstad 1974, Winter et al. 1979).

Dip-vaccination produced high antibody titres in some fish, and also produced a slight protective advantage over non-vaccinated (and sero-negative) fish. It has been shown that fish vaccinated by immersion can exhibit excellent levels of protection in the absence of detectable humoral antibodies (Croy \& Amend 1977, Sakai et al. 1984). Our results indicate, however, that when a dip-vaccinated population shows protection, at least some of the fish will have previously developed high titres. We noted a decrease in the proportion of sero-positive dip-vaccinated fish between the first and second pre-outbreak samplings. This observation agrees with work of Tatner \& Horne (1986), who found that antibodies elicited by immersion vaccination in rainbow trout declined, over time, to background levels during a period in which fish still showed protection against challenge.

A large proportion of the dip-vaccinated fish which survived the vibriosis outbreak (A/V1) were sero-positive when tested several months later. On the same occasion, samples of comparable fish which had only received one vibriosis 'exposure', via either dip-vaccination (A/V2) or outbreak survival (A/C1), yielded low proportions of, or no, sero-positive fish. This relatively long duration of circulating antibody following the second exposure suggests the occurrence of a secondary immune response.

Thuvander et al. (1987) used the present ELISA sys- tem to investigate populations of known anti-Vibrio anguillarum serotype 1 antibody positive and negative, as well as potentially positive (dip-vaccinated) rainbow trout, and found the system to be reasonably sensitive and specific. The specificity of the ELISA in field situations is, however, difficult to assess. Although minimal non-specific binding occurred in the sera of trout designated as representative negative trout, we cannot exclude the possibility that trout subsequently encountered cross-reacting antigens to $V$. anguillarum in brackish water which we could not detect. The near absence, prior to the occurrence of vibriosis mortalities, of sero-positives among non-vaccinated trout on the majority of the farms suggests, however, that false positives were not a major problem.

We used the ELISA to estimate the proportions, over time, of trout with high anti-vibriosis humoral antibody titres in vaccinated and non-vaccinated populations. Our results could only be interpreted at the population level, because individual fish were not identified and re-sampled. Although there is some risk of drawing erroneous conclusions at the individual level and thus succumbing to 'ecological fallacy' (Susser 1972), the ELISA appears to be a useful tool for assessing the immune/vibrio exposure status of vaccinated and nonvaccinated populations.

Acknowledgements. This research was supported in part by funds provided by the USDA Animal Health Act of 1977 (P.L. 95-113) and administered through the LDRL of the School of Veterinary Medicine, University of California, Davis and in part by the Swedish Council for Forestry and Agricultural Research (981-84; V18:2). Their support is gratefully acknowledged.

\section{LITERATURE CITED}

Antipa, R. (1976). Field testing of injected Vibrio anguillarum bacterins in pen-reared salmon. J. Fish. Res. Bd Can. 33: 1291-1296

Antipa, R., Amend, D. F. (1977). Inmunization of Pacific salmon: comparison of intraperitoneal injection and hyperosmotic infiltration of Vibrio anguillarum and Aeromonas salmonicida bacterins. J. Fish. Res. Bd Can. 34: 203-208

Baudin-Laurencin, F., Tangtrongpiros, J. (1980). Some results of vaccination against vibriosis in Brittany. In: Ahne, $W$. (ed.) Fish diseases. Third COPRAQ-session. Springer-Verlag, Berlin, Heidelberg, New York, p. 60-68

Croy, T. R., Amend, D. F. (1977). Immunization of sockeye salmon (Oncorhyncus nerka) against vibriosis using the hyperosmotic infiltration technique. Aquaculture 12: 317-325

Evelyn, T. P. T. (1984). Immunization against pathogenic Vibrios. In: de Kinkelin, P. (ed.) Symposium on fish vaccination, February, 1984, Paris. Office International des Epizooties, p. 121-150

Gjedrem, T., Aulstad, D. (1974). Selection experiments with salmon. I. Differences in resistance to vibrio disease of salmon parr (Salmo salar). Aquaculture 3: 51-59

Refstie, T. (1982). Preliminary results: differences between 
rainbow trout families in resıstance against vibriosis and stress. Dev. comp. Immunol., Suppl. 2: 205-209

Remington, R. D., Schork, M. A. (1970). Statistics with applications to the biological and health sciences. Prentice-Hall Inc., Englewood Cliffs, p. 26

Rosenkvist-Jensen, L. (1983). Practical experience with vaccination of rainbow trout against vibriosis. Rapp. P.-v. Réun. Cons. int Explor Mer 182: 121-125

Sakai, M., Aoki, T., Kitao, T., Rohovec, J. S., Fryer, J. L. (1984). Comparisons of the cellular immune response of fish vaccinated by immersion and injection of Vibrio anguillarum. Bull. Jap. Soc. Scient. Fish. 50: 1187-1192

Sorensen, U. B. S., Larsen, J. L. (1986). Serotyping of Vibrio anguillarum. Appl. environ. Microbiol. 51: 593-597

Susser, M. (1973). Causal thinking in the health sciences. Oxford University Press, New York, p. 60

Tatner, M. F., Horne, M. T (1986). Correlation of inmune assays with protection in rainbow trout, Salmo gairdneri, immersed in Vibrio bacterins. J. appl. Íchithyol. 3: 130-139
Thorburn, M. A., Carpenter, T E., Plant, R. E. (1987). Perceived vibriosis risks by Swedish rainbow trout net-pen farmers: its effect on purchasing patterns and willingnessto-pay for vaccination. Prev. Vet. Med. 4: 419-434

Thorburn, M. A., Carpenter, T. E., Ljungberg, O. (1988) Vibriosis vaccination of rainbow trout Salmo gairdneri at varying temperatures and seasons. I. Effects on mortality and feed conversion in four Swedish field trials. Dis. Aquat. Org. 5: 179-183

Thuvander, A., Hongslo, T., Jansson, E., Sundkvist, B. (1987). Duration of protective immunity and antibody titres measured by ELISA after vaccination of rainbow trout, Salmo gairdneri Richardson, against vibriosis. J. Fish Dis. 10: 479-486

Winter, G. W., Schreck, C. B., Mclntyre, J. D. (1979). Resistance of different stocks and transferrin genotypes of coho salmon, Oncorhyncus kisutch, and steelhead trout, Salmo gairdneri, to bacterial kidney disease and vibriosis. Fish. Bull. Ũ.S. $\bar{f} \bar{f} \cdot 795-802$

Responsible Subject Editor Dr T Evelyn; accepted for printing on November 8, 1988 